\title{
On the road toward the development of clothing size standards and safety devices for Chilean workers
}

\author{
Esteban Oñate ${ }^{\mathrm{a},{ }^{*}}$, Felipe Meyer ${ }^{\mathrm{a}}$ and Jorge Espinoza ${ }^{\mathrm{a}}$ \\ ${ }^{a}$ Ergonomics Unit, Faculty of Biological Sciences, University of Concepcion, Barrio Universitario s/n, \\ Concepción, Chile.
}

\begin{abstract}
The range of sizes used in Chile for clothing comes from criteria developed in continental Europe, mainly the EN 13402 standard. Any standard adopted by a country should consider the anthropometric dimensions of the user population, particularly to discern the ratio of garments for different size. Consequently, the purpose of this study was to propose standards for the size of clothing based on anthropometric characteristics of a sample of Chilean miners. The study was conducted in 447 male workers. The age and body weight were measured in each workers as well as their percentage of body fat. Anthropometric measurements for garments were made according to the criteria of the European Community (EN 13402-1) and ISO (85591989). Body dimensions for the design of gloves, shoes, helmets and caps, clothes that cover the upper part of the body and clothes that cover the lower part were measured. The results obtained made it possible to establish the percentage of workers falling within the range of sizes that manufacturers consider as reference. One of the main conclusions of the study is the need to carefully consider a set of complementary anthropometric measures, which can help to improve the comfort of costumes, to the extent that the providers adapt their designs to the characteristics of Chilean workers.
\end{abstract}

Keywords: Anthropometry, clothing, garment, body size, body mass

\section{Introduction}

The sizing system used in Chile mainly comes from criteria developed in Europe, whose update process began in 1996, resulting in the standard EN 13402. This standard is based on anthropometric studies from European populations carried out at the end of the 1990s. In the country, it is also frequent to make reference to the standard ISO 3635 . There is no doubt that any system adopted should consider the anthropometric dimensions of the user population, particularly to establish the proportion of garments for different sizes. A frequent criticism of workers is the discomfort of the cloth, particularly shoes and gloves. As no studies have been conducted in the country to get information of body size for clothing design, the purpose of this study is to propose standards for clothing and accessories based on anthro- pometric characteristics of the population of Chilean miners.

\section{Practice innovation}

The study was conducted on a sample of 447 male workers. Age, body weight, and percentage body fat were evaluated in each worker. Body measures for costume design were carried out according to the criteria of the European Community (EN 13402-1) and ISO (8559-1989). Dimensions for the design of gloves, shoes, helmets, caps, clothes that cover the upper tract and clothes that cover the lower tract, were considered. A Holtain anthropometer was used to carry out these measures (Holtain, Ltd. Crymmch, UK).

\footnotetext{
*Corresponding Author. E-mail: estebanonate@udec.cl
} 


\section{Findings}

Table 1 summarizes the average, standard deviation, the percentile 5 and 95 for each of the measures carried out in the workers.

Table 1. Anthropometric measurements for the design of costumes for Chilean miners

\begin{tabular}{|c|c|c|c|c|}
\hline Measure & Mean & $5 \operatorname{th}^{* *}$ & $95 \operatorname{th}^{* *}$ & S.D. \\
\hline Age (years) & 38.9 & 26.0 & 56.0 & 9.2 \\
\hline Weight (Kg) & 81.9 & 64.9 & 104.1 & 11.9 \\
\hline Height $(\mathrm{cm})$ & 171.2 & 160.5 & 181.4 & 6.5 \\
\hline $\operatorname{BMI}\left(\mathrm{Kg} / \mathrm{m}^{2}\right)$ & 27.9 & 23.0 & 34.0 & 3.3 \\
\hline Body Fat (\%) & 24.1 & 15.9 & 32.1 & 5.0 \\
\hline Head girth $(\mathrm{cm})$ & 57.6 & 54.8 & 60.5 & 1.7 \\
\hline Neck girth $(\mathrm{cm})$ & 40.7 & 36.7 & 45.9 & 2.8 \\
\hline Chest girth $(\mathrm{cm})$ & 106.4 & 95.0 & 119.0 & 7.2 \\
\hline Waist girth $(\mathrm{cm})$ & 97.8 & 85.5 & 112.7 & 8.3 \\
\hline Inner leg length $(\mathrm{cm})$ & 79.9 & 72.0 & 88.5 & 5.0 \\
\hline Arm length $(\mathrm{cm})$ & 61.5 & 56.0 & 67.4 & 3.4 \\
\hline Hand girth $(\mathrm{cm})$ & 22.4 & 20.7 & 24.7 & 1.2 \\
\hline Hand length $(\mathrm{cm})$ & 18.9 & 17.3 & 20.6 & 1.0 \\
\hline Foot length $(\mathrm{cm})$ & 25.8 & 23.9 & 28.0 & 1.2 \\
\hline Foot width $(\mathrm{cm})$ & 9.9 & 9.1 & 10.8 & 0.5 \\
\hline
\end{tabular}

Table 1 also shows the results for body weight, BMI, and the average for percentage body fat. The results of the study allowed establishing ranges of size for gloves, shoes, helmets, clothing for the upper and the lower part of the body.

To show examples of the criteria adopted for the analysis, reference will be made to the size of shoes, considering the length of the foot and to the design of clothing for the lower part of the body. In the last case the idea is to highlight the importance of body volume.

Regarding shoes, the foot length is defined as the distance between two lines parallel, perpendicular, in contact with the most prominent toe and the most prominent part of the heel, measured with the person standing barefoot and the weight distributed on both feet, as shown in Figure 1.

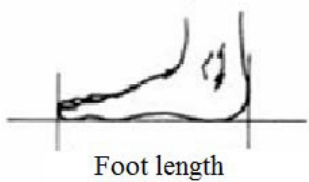

Figure 1. Illustration of the measurement of the foot length for the estimation of shoe size.

Each shoe size is suitable for a small interval of foot lengths. For most of the shoes, the size of the internal cavity should be $1.5-2 \mathrm{~cm}$ longer than the foot, but this relationship can vary according to the type of shoes and the purposes for which they are used. In Latin America, the European approach is generally used, which is regulated by the standard UNE 59850:1998. In table 2, it is possible to see the relationship between the length of the feet, at intervals of $0.5 \mathrm{~cm}$, with regard to the numbering of European and American standards. Table 2 also shows the percentage of Chilean miners, for each category.

Table 2. European and American criteria on shoe size: proportion of the sample of miners in each category.

\begin{tabular}{|c|c|c|c|}
\hline USA & $\begin{array}{c}\text { Europe / } \\
\text { Latin } \\
\text { America }\end{array}$ & $\begin{array}{c}\text { Length } \\
(\mathrm{cm})\end{array}$ & \% Workers \\
\hline 6.0 & 38.5 & $22-5-23.0$ & 0.9 \\
\hline 6.5 & 39.0 & $23.0-23.5$ & 1.3 \\
\hline 7.0 & 40.0 & $23.5-24.0$ & 4.9 \\
\hline 7.5 & 40.5 & $24.0-24.5$ & 9.4 \\
\hline 8.0 & 41.0 & $24.5-25.0$ & 10.7 \\
\hline 8.5 & 42.0 & $25.0-25.5$ & 16.6 \\
\hline 9.0 & 42.5 & $25.5-26.0$ & 13.4 \\
\hline 9.5 & 43.0 & $26-0-26.5$ & 16.3 \\
\hline 10.0 & 44.0 & $26.5-27.0$ & 10.3 \\
\hline 10.5 & 44.5 & $27.0-27.5$ & 6.5 \\
\hline 11.0 & 45.0 & $27.5-28.0$ & 4.7 \\
\hline 11.5 & 45.5 & $28.0-28.5$ & 2.9 \\
\hline 12.0 & 46.0 & $28.5-29.0$ & 1.6 \\
\hline 12.5 & 47.0 & $29.0-29.5$ & 0.2 \\
\hline 13.0 & 47.5 & $29.5-30.0$ & 0.2 \\
\hline
\end{tabular}

The second example is related to the design of clothing for the lower part of the body. One of the most important measures for the design of trousers, underwear, boxers or other clothing, is the circumference of the waist. Table 3 shows the percentage of trousers per size required for this population. As it can be seen, the majority of workers qualify for large size which is mainly due to overweight. Figure 2 shows the correlation between body weight and waist contour, revealing a high association between these two variables.

When body size increases because an increment of body volume, which is often the case, some additional steps have to be considered for comfort, mainly because the inner leg length is not proportional to the characteristics of the worker. In other words, the relationship between inner leg length and stature, illustrated in Figure 3, shows a high correlation because both are linear measurements. Different is the situation for inner leg length versus waist contour. As it can be seen in Figure 4, the correlation is very low. As expected this is due to the fact that the increment of body volume in the adult is not associated with changes in stature. In such a case, if the standard dimension of the inner 
mension of the inner part of the leg is kept, the trousers to fit the waist contour of the workers, will be too long and uncomfortable.

Table 3. Sizes according to the waist girth $(\mathrm{cm})$ and percentage of the sample of workers in every size.

\begin{tabular}{|c|c|c|c|c|}
\hline U.S. Size & $\begin{array}{c}\text { European } \\
\text { Size }\end{array}$ & Size & $\begin{array}{c}\text { Waist girth } \\
(\mathrm{cm})\end{array}$ & $\%$ \\
\hline 28 & 38 & $\mathrm{~S}$ & $70-75$ & \\
\hline 30 & 40 & $\mathrm{~S}$ & $75-80$ & 0.7 \\
\hline 32 & 42 & $\mathrm{M}$ & $80-85$ & 2.9 \\
\hline 34 & 44 & $\mathrm{M}$ & $85-90$ & 15.4 \\
\hline 36 & 46 & $\mathrm{~L}$ & $90-95$ & 19.9 \\
\hline 38 & 48 & $\mathrm{~L}$ & $95-100$ & 25.1 \\
\hline 40 & 50 & $\mathrm{XL}$ & $100-105$ & 19.2 \\
\hline 42 & 52 & $\mathrm{XL}$ & $105-110$ & 9.4 \\
\hline 44 & 54 & $\mathrm{XXL}$ & $110-115$ & 4.0 \\
\hline 46 & 56 & $\mathrm{XXL}$ & $115-120$ & 1.6 \\
\hline 48 & 58 & XXXL & $120-125$ & 1.3 \\
\hline 50 & 60 & XXXL & $125-130$ & 0.4 \\
\hline
\end{tabular}

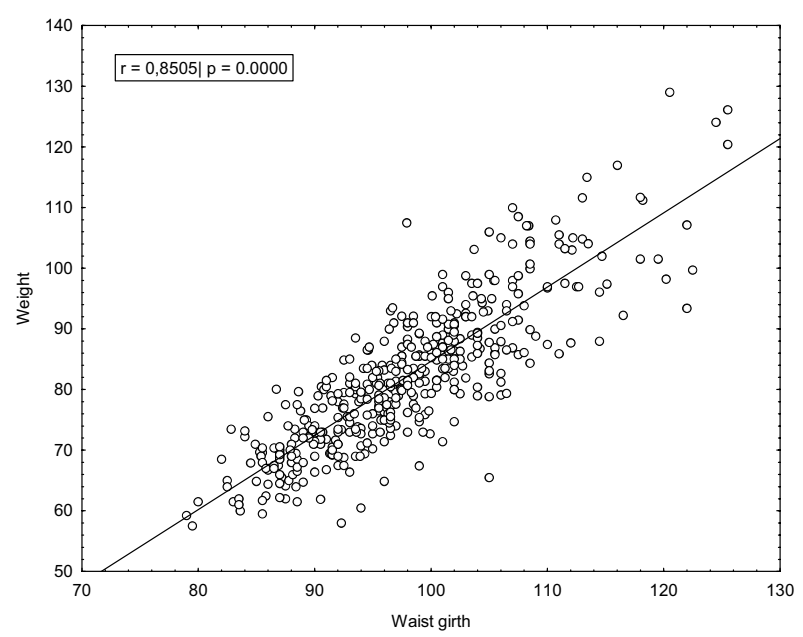

Figure 2. Relationship between body weight and waist girth of the sample of workers

\section{Discussion}

It is important to highlight that one of the factors affecting sizes of clothing, is the body volume of the miner's population in Chile who have a significant trend to overweight or obesity. While the issue of obesity has implications on health and physiological load at work, it is also a factor that produces a significant displacement toward the bigger sizes of clothes.

The findings of this study suggest to analyze carefully a group of complementary anthropometric measurements, which can help to improve clothing's comfort, in the hope that the providers will adapt their designs to the characteristics of Chilean workers.

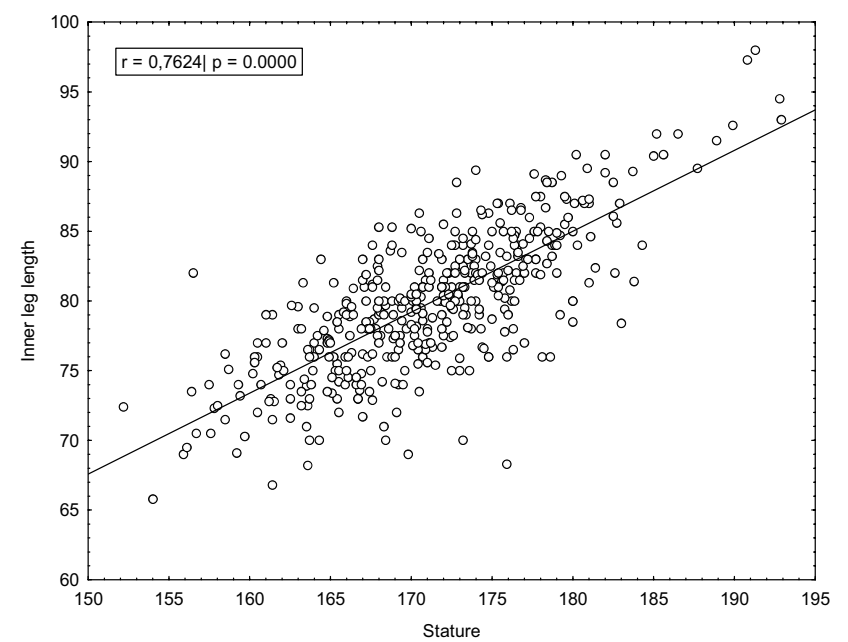

Figure 3. Relationship between inner leg length and stature in a sample of 447 Chilean miners.

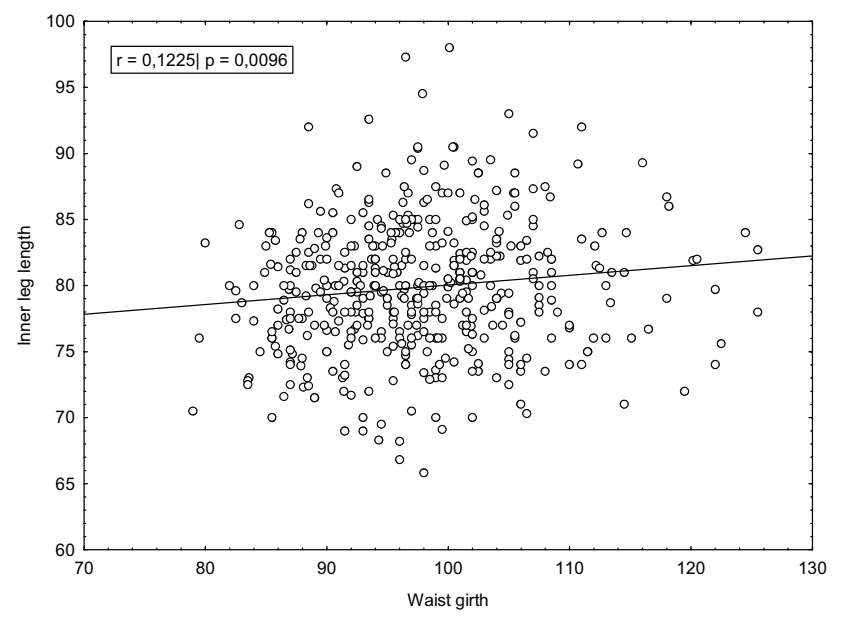

Figure 4. Relationship between inner leg length and waist girth in a sample of 447 Chilean miners.

\section{References}

[1] International Organization for Standardization (1981). Size designation of clothes - Definitions and body measurement procedure. ISO 3635:1981. Switzerland, Geneva.

[2] International Organization for Standardization (1989) Garment construction and anthropometric surveys - Body dimensions. ISO 8559:1989. Switzerland, Geneva.

[3] European Standard UNE (1998). Footwear. Designation of Sizes. Main Characteristics of The Continental System. UNE 59850:1998. Spain, Madrid.

[4] European standard UNE-EN (2002). Size designation of clothes. UNE-EN 13402: 2002. Spain, Madrid. 